pación no ennoblecía; dentro de la vida hispano-cristiana, sí; nos lo pone de manifiesto la estructura semítica de fijodalgo, con una realidad que en este caso no podemos desmembrar en forma árabe y contenido románico.

Princeton University.

Américo Castro

\title{
SOBRE ALGUNOS INSTRUMENTOS DE MÚSICA MENCIONADOS POR GERVANTES
}

Cervantes menciona en diferentes obras algunos instrumentos de la familia de las trompetas que han sido deficientemente identificados. La familia completa, en tiempos de Cervantes, constaba de seis instrumentos; en su clasificación italiana, que Cervantes debió conocer, se denominaban clarino, cornetto, lituus, principale, tromba y corno da tirarsi. Este último no era réalmente un corno, sino una trompeta de varas (con tudel movible). La tromba era la trompeta castellana. Cornetas y trompetas tienen denominaciones especiales en Cervantes. Si el sacabuche denominaba en Cervantes al trombón de varas solamente, o a la trompeta de esta clase (Zugtrompette, en alemán), no puede saberse. De los tres instrumentos similares, bocina, cuerno y trompa, sólo la manera de estar mencionados puede sugerir su identificación. Trompetas y cornetas están usadas por Cervantes, en algunos casos, como sinónimos. En cuanto a la trompeta bastarda, constituye un pequeño problema cervantino que, probablemente, ha estado mal planteado. Quizá puedan dar alguna luz las observaciones siguientes.

BOCINA. GUERNo.- - La bocina y los cuernos están mencionados por Cervantes (Quijote, II, cap. xxxIv) juntamente con los demás instrumentos de su clase, cornetas, clarines, trompetas, en un alarde de erudición bélica, aunque se trata en este caso de un estrepitoso fingimiento que tiene por objeto poner pavor en el ánimo del caballero y de su escudero. El nombre de bocina es clásico, pero en tiempos de Cervantes este instrumento no era ya la tuba curva, recorvada, instrumento utilizado para sus señales por la infantería romana y del cual se ha encontrado algún ejemplar en Pompeya, hoy conservado en el Museo de Nápoles. Según Sachs, hacia el año rooo y bajo la influencia de los añafiles árabes, se enderezó el tubo de la bocina, alargándosele y dotándosele de una campana ancha. Se construyeron en dos tamaños. El más pequeño había dado la trombetta, que se encuentra en DANTE (Inf., XXI, I 39). El más grande conservaba su nombre original en Francia como buisine, y en medio alto alemán como busîne, de donde posaune, el actual trombón. Para este comentarista, al añafil, musulmán (al nafîr) era el cor sarrazinois de los poetas franceses medievales. Originalmente, el cuerno es el más simple de los instrumentos: se encuentra en la Biblia como šofar o qeren, cuerno de macho cabrío o de carnero al que se ha añadido una embocadura. 
Sumerios y egipcios lo conocían ya. Homero no menciona ningún instrumento semejante a bocinas ni cuernos. En la Europa central parece que entraron por Bizancio, en calidad de instrumentos elegantes hechos de un colmillo de elefante (olifante), hacia el siglo x u xI, según Sachs. El cuerno de Roldán era un olifante, instrumento del que se conservan hoy bastantes ejemplares. En los manuscritos de los Comentarios al Apocalipsis del BeAto de Liébana hay multitud de ilustraciones donde se ven ángeles que tocan cuernos, pero, por su tamaño, de no ser imaginario, no parece que fueran olifantes, sino simples cuernos de buey. Por su denominación de olifantes no se los conoce en la organografía española, pero la acción de hacer sonar un instrumento de viento (y no solamente un cuerno) se entendía como cornar en tiempos del rey de Aragón don Juan I, últimas décadas del siglo xIv. La longitud, anchura y grado de curvatura de los cuernos varía mucho en los manuscritos, desde los mencionados hasta el siglo xIv. En las Cantigas se encuentran cuernos recorvados de distintos tamaños, siempre mayores que los cuernos de caza naturales. Su dimensión y curvatura se logra fabricándolos en piezas diferentes, que los miniaturistas detallan. En un caso, uno de los mayores cuernos de las Cantigas posee un depósito de aire, una vejiga, cerca de la embocadura, que se infla considerablemente antes de producir el sonido, el cual puede así regularse. Hay añafiles en las Cantigas, pero no olifantes, que eran de pequeño tamaño. Si los bizantinos los habían importado de Oriente, es curioso que los árabes no los conociesen. En la catedral de Zaragoza se conserva uno, bellamente labrado, según era costumbre; esa decoración parece más bien gótica. De tal instrumento se dice haber sido el olifante de Gastón de Bearn, y se detalla como obra bizantina del siglo xII. En el Quijote (I, cap. II) era instrumento rústico, en manos de porqueros.

CORNETA.-Un olifante habría de ser, por naturaleza, un cuerno pequeño, es decir, un cornetto, y en efecto hay durante el Renacimiento cornetas de marfil, casi rectas, por oposición a las cornetas tuertas, más o menos recorvadas. Esta curvatura se obtenía uniendo dos o más secciones de la corneta; para afirmarlas solían recubrirse con una tira de badana, arrollada en toda la longitud del instrumento. Con el uso, la badana se ennegrecía considerablemente, dando lugar a la denominación de cornetas negras. Cervantes menciona una corneta de posta, anunciadora de la llegada del Duque mientras Sancho come en su ínsula. La denominación es italiana, cornetta di postiglione, aun cuando, como se verá en seguida, los postillones no tocaran, propiamente, cornetas, y el cornet de poste (Posthorn), que es un instrumento de pistones, sea posterior a Cervantes. Las diferentes formas de las cornetas están diseñadas por Praetorius en su Syntagma musicum (I6I5-16I9) en tres maneras (bajo el nombre genérico de Zinken): una recta; otra ligeramente recorvada, aproximadamente de las mismas dimensiones que la anterior, y otra recorvada en forma de S, de grandes dimensiones, denominada Corno, Gross Tenor Cornet. Las dos especies, recta y curva, se construían en dos tamaños, y, en cuanto a la gran corneta en forma de S, era la corneta tuerta, especie dentro de las cornetas negras. Algunos cuernos, casi rectos, de los Beatos 


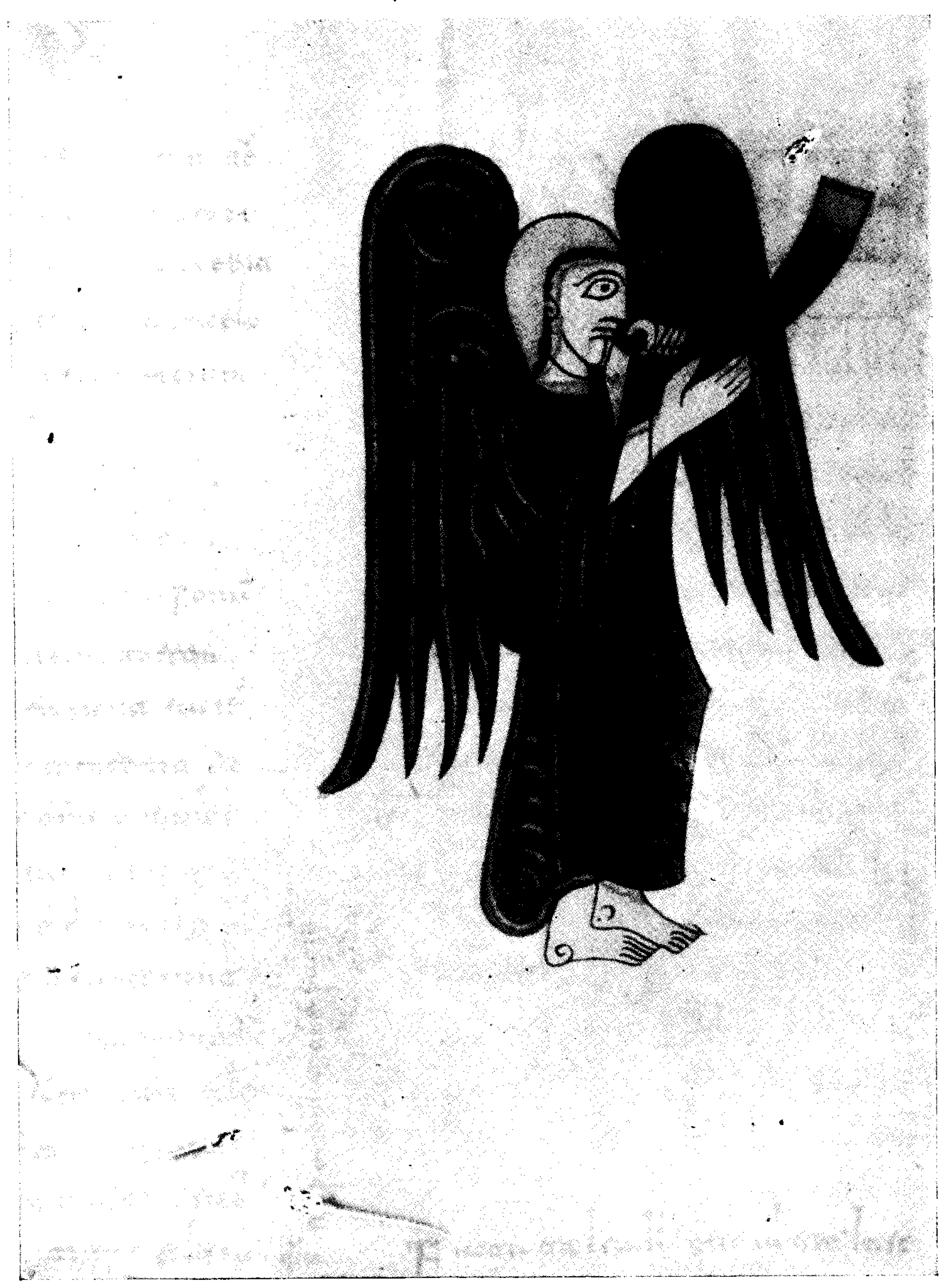

A. Cuerno. Beato de Liébana: Comentarios al Apocalipsis. Siglo x (según J. Domínguez Bordona). Fotos de Arxiu Mas, de Barcelona. 


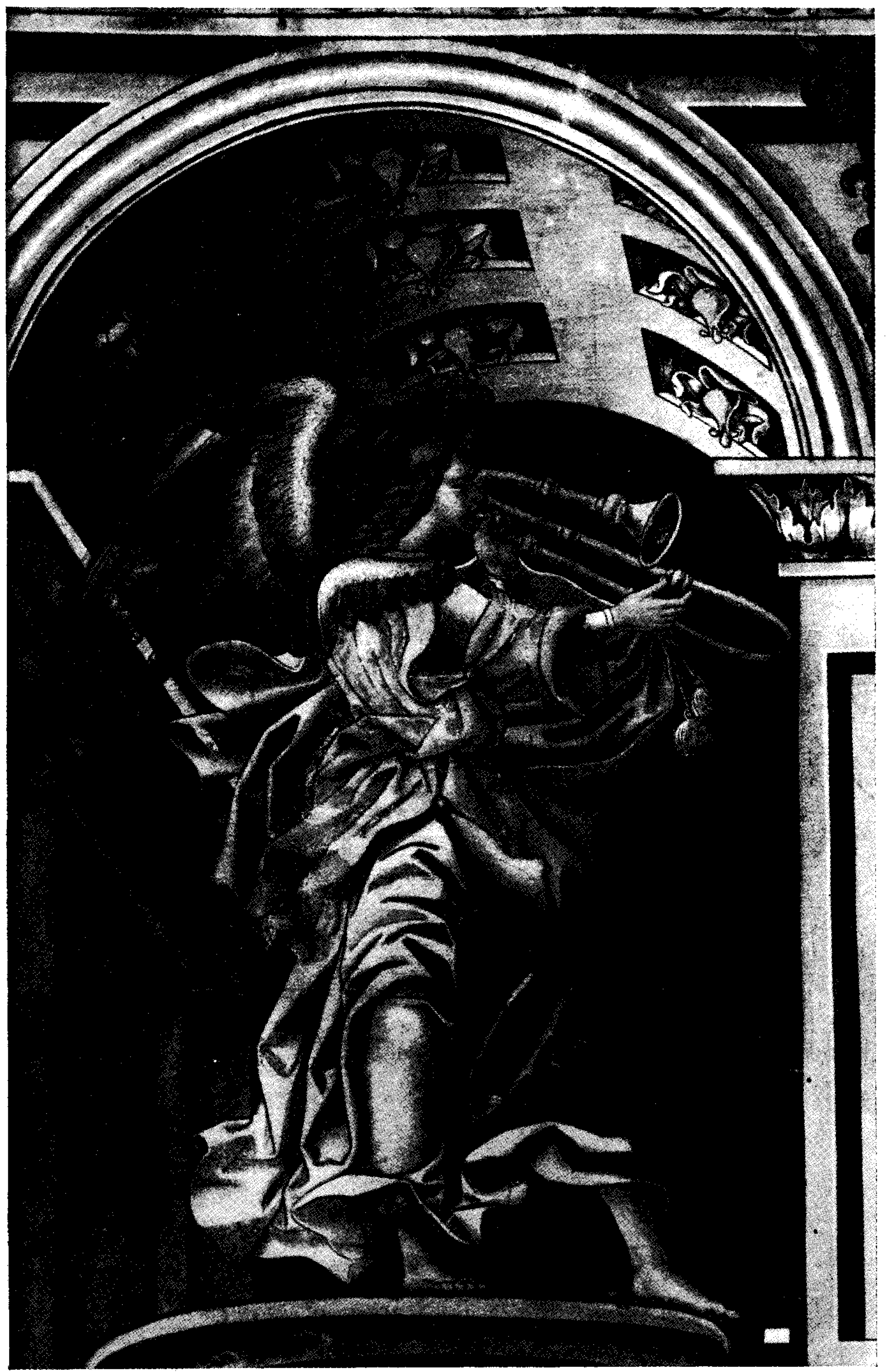

B. Trompeta recurvada, posiblemente con tudel movible. Pintura atribuída a Santacruz, siglos xv-xvi. Iglesia de San Pedro, Ávila. Fotos de Arxiu Mas, de Barcelona. 


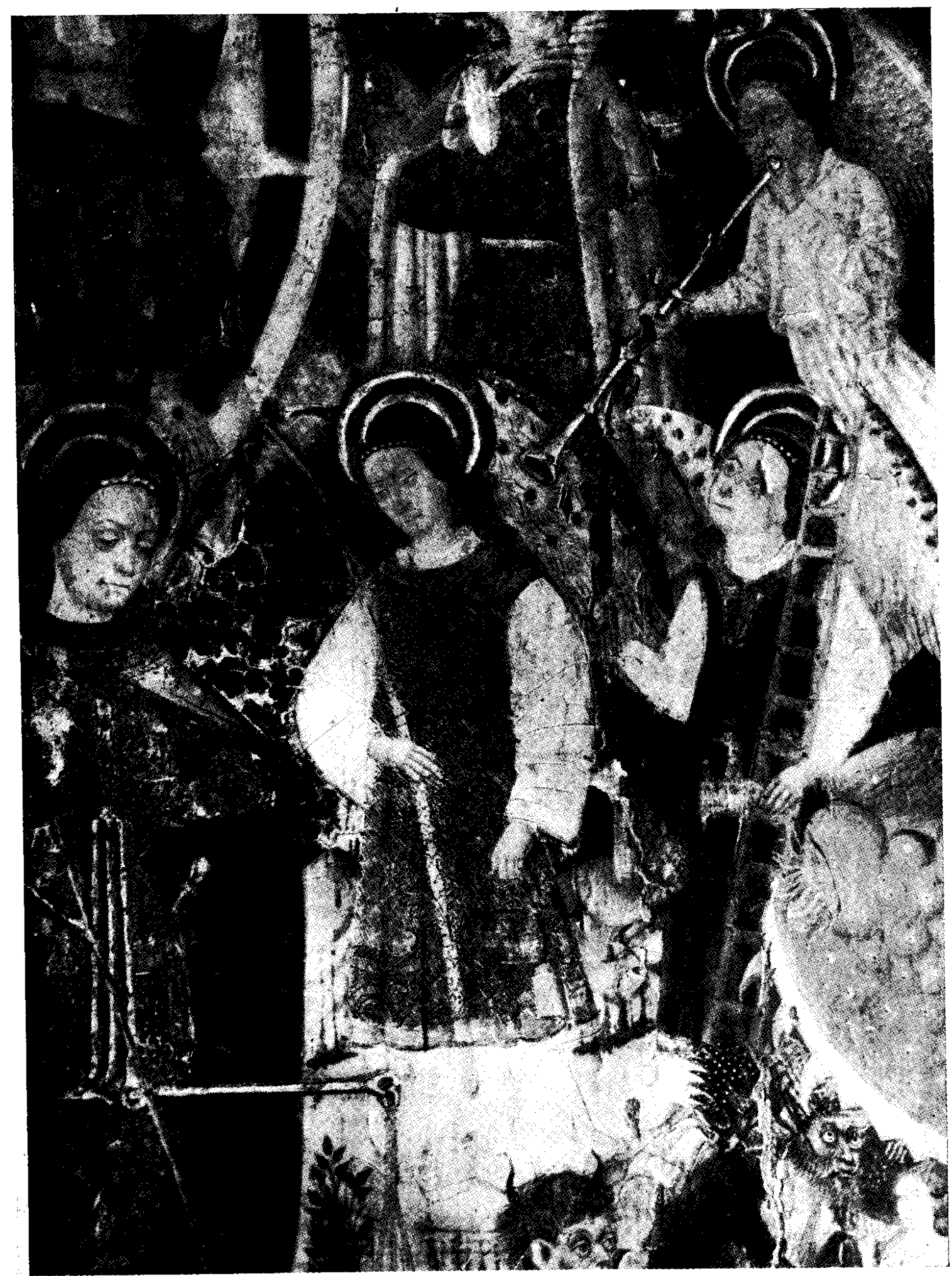

C. Trompeta recta, posiblemente con tudel movible. Retablo del siglo xv. Iglesia de los Templarios. Palau del Vidre, Argeliers, P. O.; Francia. Fotos de Arxiu Mas, de Barcelona. 


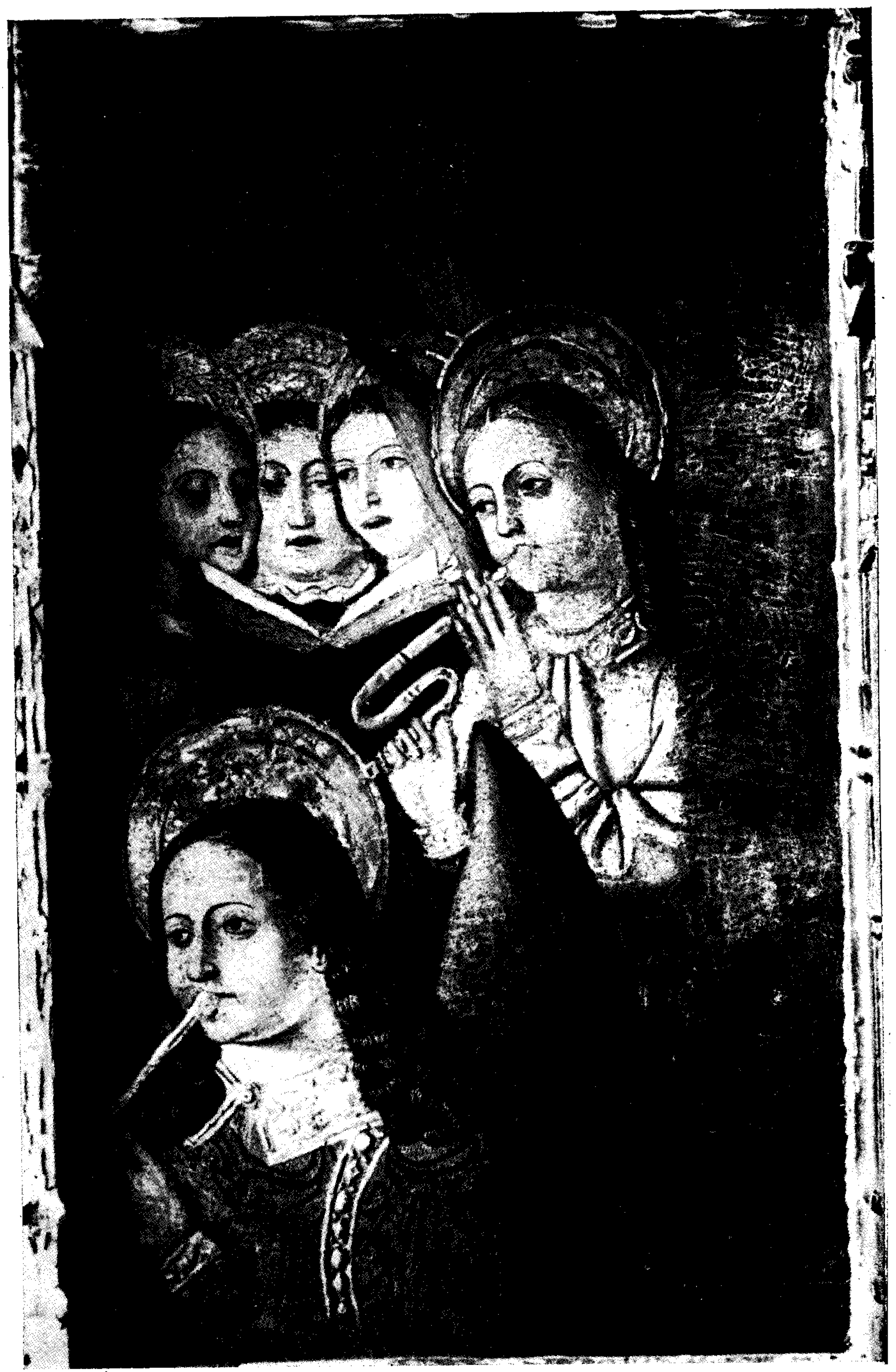

D. Trompeta recorvada, posiblemente con tudel movible, pintura del siglo xv aproximada. mente. Zaragoza, colección particular. Fotos de Arxiu Mas, de Barcelona. 
podrían considerarse como cornetas, pero la fecha parece demasiado temprana. Una pintura que se conserva en Tarrasa, de autor anónimo, del siglo xv probablemente, muestra un ángel que toca una descomunal corneta tuerta. De la misma época es la pintura atribuída a Jaime Lana (1492) que se encuentra en la iglesia de Santa María de Borja, donde tres ángeles tocan sendas cornetas rectas de un tamaño notoriamente grande. Cervantes no hace especial distinción entre cornetas y trompetas. En el párrafo citado del Quijote menciona tanto las unas como las otras, junto a los clarines, que son la especie más aguda de las trompetas y que en el Viaje del Parnaso proporcionan "dulcísima armonía"; pero en El retablo de las maravillas, lo mismo le da que sea una trompeta o una corneta la que suene dentro del teatro anunciando a un "furrier de companías". Y es a una trompeta negra a la que Cervantes alude en La casa de los celos (jornada II), evidentemente por corneta negra.

TROMPA. TROMPETA.-La trompa, en España, antecede a la trompeta. Trompas e naffils figuran en 1380 en los documentos referentes a la entrada en Barcelona de doña Violante de Bar, esposa del infante don Juan, $\mathrm{y}$, en otro documento de I 394 , se denomina trompadors a los tañedores de dicho instrumento. Trompas e annafiles salen, con atambales, a recibir a Don Amor en el libro del Arcipreste de Hita. La simultaneidad de ambos instrumentos es elocuente, porque los añafiles eran instrumentos rectos y las trompas eran las buccinae que, como acabamos de ver, eran cur-

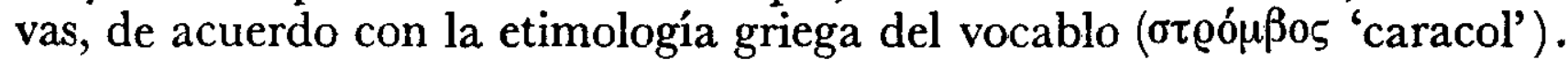
Al verbo cornar sucederá ahora el de trompar y los instrumentistas se llamarán trompadors en Cataluña, con la especificación, en las Ordenanzas dels jutglars de don Pedro III de Aragón (siglo XIII), de que, de cuatro juglares trompadors, el cuarto lo sea de trompeta. En el siglo xv las cuentas en la región catalana se latinizan y en vez de trompa aparece la palabra tuba (1454); en 1455, la de tubicina. En 1456 lo que se menciona ya son les trompetes (JulíAN dE GHÍA, La música en Gerona, I886). Que el vocablo trompa tiene un sentido genérico todavía en el Renacimiento, se ve en un manuscrito de $155^{\circ}$ que perteneció a Barbieri y después a Gayangos (copia de Barbieri en la Biblioteca Nacional de Madrid, Papeles de Barbieri, 14060) en el cual se describen las "Fiestas de Bins hechas por la serenísima reina de Hungría" en Bruselas, a I 8 de marzo de i 550, para obsequiar a Carlos V y a su hijo don Felipe. "Trompas sonaron - dice- - y venían los trompetas vestidos de raso blanco y encarnado". "Allí figura una 'corneta de marfil', que se tocaba para demandar batalla los caballeros". Caballeros y damas entran danzando la Alemana y "Luys venía tañendo y cantando A las armas moriscote", el romance cantado a la vihuela por Miguel de Fuenllana, músico que fué en la corte de Felipe II (también por Diego Pisador y, a cuatro voces, por Cristóbal Morales, todos hacia la fecha indicada).

Tantas trompetas salieron a recibir a la princesa de Navarra en $\mathrm{Za}$ ragoza en el año de 1479 , que parecían asordar el mundo, junto con los atabales, como en la exhibición de los títeres de maese Pedro. La trompeta, frecuentemente ronca, triste y ominosa en Cervantes (como el cuerno), tiene en el Viaje del Parnaso el papel exultante quc ya señalaba Vir- 
gilio para la broncínea bocina, que, en Juan de Padilla es "ronca bocina" y tiene un papel fatídico en la Danza de la Muerte. Solamente una vez escribe Cervantes trompa, instrumento ya sustituído en su tiempo por la trompeta, y es cuando en El celoso extremeño se habla de la trompa de Paris, que se entiende ser el birimbao o guimbarda, pero que pudiera ser una trompetilla que, en el Criticón, figura entre otras brujerías.

LA TROMPETA BASTARDA.-Infinidad de especies siguieron en seguida. Entre ellas esa trompeta bastarda capaz de desasosegar a filólogos y musicólogos, que no encuentran manera de identificarla. La casa de los celos, jornada III; Viaje del Parnaso, vir; Los baños de Argel, jornada I. El Marqués de Santillana la cita juntamente con los clarones, suponiéndose que los clarones sean los clarines, más que por la morfología del vocablo, que no habrá de designar un aumentativo, por su procedencia del clairon francés. Rodríguez del Pulgar, poco después que el Marqués, dice simplemente: "Toca, toca, cavalga / essos trompetas clarones", que pudieran no ser tan agudos y en los cuales el género de los clarones ha pasado a su antecedente. La acepción más recibida para la trompeta bastarda es la que procede de Covarrubias, quien, a lo menos en materia musical se inventa tranquilamente las cosas o admite la voz popular. Como hay algunas acepciones de bastardas aplicadas a otras cosas, en un sentido intermedio entre lo más grande y lo más chico, Covarrubias describe la trompeta bastarda como instrumento intermedio entre la trompeta ordinaria, "que tiene el sonido fuerte y grave, y el clarín, que lo tiene delicado y agudo". La explicación, sin embargo, parece ser imaginaria, porque había trompetillas bastardas (Historia del saqueo de Cádiz por los ingleses en 1596, escrita por Fr. Pedro de Abreu. Papeles de Barbieri, núm. 14068). La explicación viene por otro lado. Una trompette serpentine que existe en el Museo Instrumental de Bruselas (núm. I683), aunque de construcción moderna, me parece que da la clave del problema, pues que bastar$d a$, a lo menos hasta mediado el siglo XIx, y quizá sólo popularmente, se decía en España a las serpientes, que habrían de estar enroscadas para admitir la comparación con las trompetas ${ }^{1}$. Trompetas así, de pequeño tamaño, se encuentran en la obra Musica Getutscht ( 15 I I ), y en el tratado de Praetorius Syntagma musicum (vol. I, i6 I $_{5}$ ) con el nombre de Jäger-Trompete. Lo que importa en este enroscamiento es que las vueltas (cuatro, generalmente) están muy apretadas, a diferencia de los corni o Hörner (cor de chasse, Waldhorn), que tienen muy anchos sus círculos. Brueghel (o un imitador suyo) las pinta en su cuadro El Oído, perteneciente a una colección privada de Madrid. Lo característico de ellas consiste en la gran capacidad de su juego, ágil y brillante, en una tesitura tan aguda que se piensa que fuese esa la utilizada por Bach en el segundo de sus Conciertos de Brandeburgo. Sus tañedores alcanzaban gran reputación. Uno de ellos fué Gottfried Reiche, Stadpfeifer muy notable del tiempo de Bach, cuyo retrato publica CH. S. Terry en su libro Bach's Orchestra (Londres, I932, págs. 48-49). El trompetista sostiene

1 "Bastardo, da, adj.: ... culebra, boa" (Ramón Campuzano, Diccionario manual de la lengua castellana, Madrid, 2a. ed., 1852, s. v.). 
en su mano derecha una trómpeta serpentina, un poco mayor que la que Praetorius dibuja en su lámina (reproducida páginas antes por Terry). Tiene cuatro anillos, que dejan paso a la mano para que sujete el instrumento, es decir, que no son tan cerrados como en Praetorius, pero se echa de ver con facilidad que el dibujo de éste es muy mediocre y que la pintura del músico, por E. G. Hausmann, era de buen pincel. Entre la vuelta más externa y la embocadura se ve un círculo pequeño que corresponde a un tudel movible, a fin de cambiar el tono. Un papel que el músico tiene en su mano izquierda muestra un pasaje cuya agilidad confirma la virtuosidad del trompetista. Pedrell, siguiendo a Covarrubias, y los demás a Pedrell, inventaron o aceptaron una historia según la cual había en tiempos de Cervantes dos clases de trompetas: la española, también llamada bastarda, y la italiana; aquélla más susceptible de habilidades que la segunda. Pedrell, en su Organografía musical an-

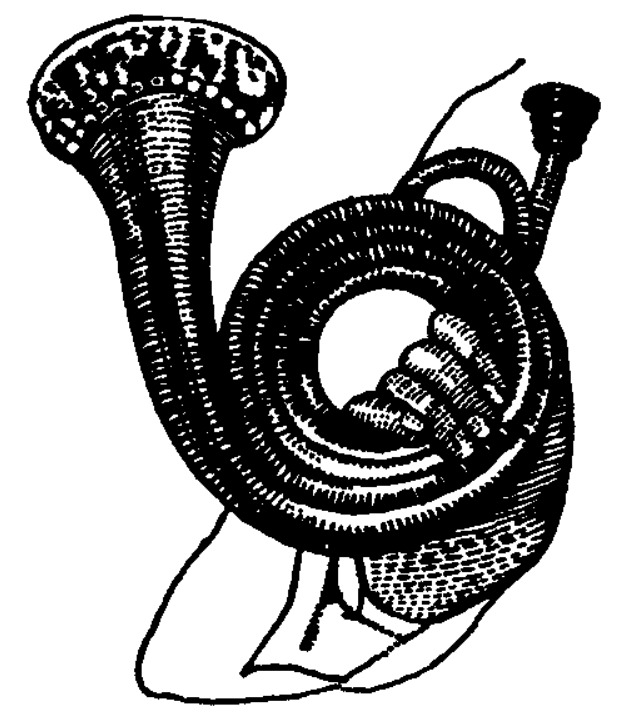
tigua española (número 70, pág. 133), publica unas "Cartas de examen de trompeteros de trompeta bastarda y de trompeta italiana", identificando la bastarda con la española. Pero la identificación es gratuita. Se basa en un título que alguien (Barbieri, probablemente) puso a sendas cartas; a la primera (Madrid, I $_{6} \mathrm{I}_{3}$ ): "Carta de examen de trompeta bastarda", y a la segunda (idem): "Carta de examen de trompeta italiana". En la primera carta no se habla ni se cita ninguna clase de trompeta bastarda. Se dice, simplemente, que cierto Antonio García tañó la trompeta española a unos trompetistas "italianos", entendiéndose del instrumento italiano, aunque dos de ellos, Leonardo Capuano y Francisco Lombardo, serían probablemente italianos y el tercero, Juan Marcos Castellanos, sería español. Por qué se ha puesto en el epígrafe de la carta "trompeta bastarda" es cosa que ignoramos. Pedrell, que no dice de dónde proceden estos documentos, mutila el texto, de manera que cuando se dice: "nos tañó con la dicha trompeta española" parece en efecto que se alude a la bastarda mencionada en el epígrafe del coleccionador de los documentos. Estas cartas probablemente proceden de los papeles inéditos de Barbieri que se conservan en la Biblioteca. Nacional de Madrid. Barbieri dió a Pedrell, en una carta que se conserva entre ellos, una cantidad muy grande de informes que éste utilizó (incluso con sus errores) sin mencionar su origen, en el libro mencionado, impreso en Barcelona en 1901, años después de la muerte de Barbieri. La competencia del gran musicólogo y compositor en materia de instrumentos era tan grande que otros escritores como Julián de Chía acudieron también a él para resolver sus dudas en los apuntes históricos, antes citados, sobre La música en Gerona, uno de cuyos apéndices fué redactado por Barbieri (en I 883). En él se dice (pág. 121): "también había coplas de trompadors que concertaban artísticamente sus trompetas españolas, italianas o bastardas". No se desprende de ahí que las bastardas fueran necesaria- 
mente ni las españolas ni las italianas; pero, en todo caso, la conjunción, si no es disyuntiva, indica que las bastardas son las italianas, al revés de lo entendido por Pedrell. Y, en efecto, un escritor alemán llamado Eichbơrn, perito en la materia, a quien Terry menciona (op. cit., pág. 48), al describir las varias especies de trompetas usadas a fines del siglo XVII y comienzos del xvitr, coloca en el último lugar de su lista una "trompeta italiana o gewundene"; es decir la enroscada serpentinamente como las bastardas. Otro especialista, Altenburg, también mencionado por el escritor inglés, coincide en la italianidad de la trompeta enroscada o gewundene, detallando sus méritos y su gran agilidad de juego.

EL SAGABUChe.-Normalmente se entiende que el sacabuche es el trombón de varas, bajo de la familia de las trompetas. Pero había sacabuches de diversos tamaños, el más agudo de los cuales tenía el tamaño de una trompeta grande. No es posible entender, en Cervantes, a qué especie de sacabuches alude, aunque el hecho de que lo mencione a solo (en $E l$ rufián dichoso, jornada I y como capaz de gran agilidad - deducida de la mención - pudiera permitir la suposición de que se tratara de una trompeta de varas, o Zugtrompette, de la cual no se encuentra ni un solo ejemplo, salvo error, en la literatura española. Sin embargo, esta clase de trompetas era conocida en España. Otra cosa sería de extrañar, y, atendiendo a su mecanismo, merced al cual el tudel movible entraba y salía fácilmente en la parte alta del instrumento, es posible que, a lo menos popularmente, fueran designadas tanto las trompetas como el trombón con el mismo nombre, que venía de Francia (sacquebute). A la vista de varios ejemplos presentados por KURT SACHs en su artículo sobre la tromba (o corno) da tirarsi (slide trumpet) titulado Chromatic Trumpets in the Renaissance (en $M Q$, enero de 1950) y de las explicaciones que Sachs da sobre la manera de sostenerse y de manejar el instrumento, creo encontrar varios ejemplos de estas trompetas en la iconografía española, muy abundante en materia de cuernos, bocinas, trompetas encorvadas, cornetas rectas y tuertas, en donde se sigue bien la historia del instrumento, pero no tan generosa en aquellos otros casos.

1. Trompeta en doble vuelta (U-turn). El tudel movibles se observa claramente, sujeto por la mano izquierda del ángel tañedor. Ávila, Iglesia de San Pedro, pintura atribuída a Santacruz, siglos XV-XvI.

2. Zaragoza, colección particular. Pintura aproximadąmente de los siglos XV-Xvi. Un ángel toca una trompeta encorvada en $\mathrm{S}$ corta, con la posición de la mano izquierda cerca de la embocadura que Sachs señala para las slide-trumpets.

3. Trompeta recta; todo el tudel fuera. Palau del Vidre, antigua iglesia de los Templarios, retablo del siglo xv.

4. Trompeta en doble curva (U-turn), todo el tudel fuera. Valencia, Obras de Publio Virgilio Marón, vol. 748. Biblioteca de la Universidad. Pergamino miniado del siglo xv.

5. Játiva, Colegiata, Tabla de Hernán Yáñez de la Almedina, siglo xvi. Curiosos ejemplares de trompetas, posiblemente de tudel mo- 
vible, con una especie de saco de aire o tela abombada, cuya utilidad desconocemos.

Es posible encontrar más ejemplos; pero, por ser dudosos, no creemos de interés mencionarlos.

El Colegio de México.

Adolfo Salazar

\section{FRAY LUIS DE LEÓN: "VE CÓMO EL GRAN MAESTRO ..." (ENMIENDA)}

Es enmienda de detalle confirmadora de la tesis sustentada. ${ }^{1}$

Un viejo error de lectura en la Oda de Salinas se me quedó fijado inexcusablemente hasta que Dámaso Alonso me lo ha hecho ver: la estrofa 6", "Y como está compuesta / De números concordes, luego envía / consonante respuesta ...", no tiene por sujeto gramatical a la música de Salinas, sino al alma, que se pone a cantar al oír la divina música de las esferas. Dámaso Alonso me señala este pasaje decisivo de los Nombres de Cristo, Príncipe de Paz; "así el ánimo bien concertado dentro de sí y que vive sin alboroto y tiene siempre en la mano la rienda de sus pasiones y de todo lo que en él puede mover inquietud y bullicio, consuena con Dios y dice bien con los hombres y teniendo paz consigo mismo la tiene con los demás."

Así, pues, la estrofa interpolada, "Ve cómo el gran maestro", ni siquiera rompe el hilo sintáctico entre la cuarta y la sexta (cosa que no solamente mi descuido sino el de los comentaristas que se han ocupado de esto aceptaban): las tres forman una secuencia o enumeración en la que el alma es el sujeto gramatical común. La autenticidad de la maravillosa estrofa pierde así su última sombra de objeción.

Harvard University.

Amado Alonso

1 Véase $N R F H, I V, 4$, págs. 39 1-394. 